\title{
HUBUNGAN KARAKTERISTIK DENGAN PENGETAHUAN IBU TENTANG DAMPAK PERNIKAHAN DINI TERHADAP KESEHATAN REPRODUKSI
}

\author{
Ana Pujianti Harahap, Aulia Amini, Catur Esty Pamungkas \\ Program Studi DIII Kebidanan, Universitas Muhammadiyah Mataram \\ ana.harahap87@gmail.com
}

\section{INFO ARTIKEL}

Riwayat Artikel:

Diterima:16-10-2017

Disetujui:19-11-2017

\section{Kata Kunci:}

Pernikahan dini

Kesehatan Reproduksi

\section{ABSTRAK}

\begin{abstract}
Abstrak: Penikahan merupakan pertalian yang sah antara seorang lelaki dan seorang perempuan yang hidup bersama dan tujuannya membentuk keluarga dan melanjutkan keturunan. Pernikahan dini merupakan salah satu masalah keluarga yang belum terpecahkan dan sampai saat ini angkanya cukup tinggi. Perempuan muda di Indonesia dengan usia 10-14 tahun menikah sebanyak 0,2 \% atau lebih dari 22.000 wanita muda berusia 16-20 tahun di Indonesia sudah menikah. Desain penelitian yang digunakan adalah analisis deskriptif dengan pendekatan cross sectional, dilaksanakan di Kelurahan Gunung Sari. Sampel penelitian ibu yang memiliki anak remaja umur 16-20 tahun di Kelurahan Gunungsari berjumlah 43 orang. Teknik pengambilan sampel secara total sampling. Instrumen penelitian menggunakan kuesioner. Pengumpulan data menggunakan data primer dan sekunder. Analisis data meliputi analisis univariat dan bivariat dengan uji Chi Square dengan tingkat kemaknaan $\mathrm{p}<$ 0,05.Analisis bivariat menunjukkan bahwa ada hubungan yang bermakna antara hubungan yang bermakna secara statistik antara pendidikan ibu dengan pengetahuan tentang dampak pernikahan dini pada kesehatan reproduksi ( $p$ value 0,038<0,05). Pendidikan ibu yang rendah dapat menyebabkan pengetahuan ibu rendah tentang dampak pernikahan dini pada kesehatan reproduksi.
\end{abstract}

\section{A. LATAR BELAKANG}

Penikahan merupakan pertalian yang sah antara seorang lelaki dan seorang perempuan yang hidup bersama (bersetubuh) dan yang tujuannya membentuk keluarga dan melanjutkan keturunan. Salah satu dari tujuan pernikahan atau perkawinan adalah untuk memperoleh keluarga yang sakinah. Sakinah artinya tenang, dalam hal ini seseorang yang melangsungkan pernikahan berkeinginan memiliki keluarga yang tenang dan tentram. Karena pernikahan adalah sarana efektif untuk menjaga kesucian hati agar terhindar dari perzinahan (Shomad,2010). Pernikahan dini merupakan salah satu masalah keluarga yang belum terpecahkan dan sampai saat ini angkanya cukup tinggi. Pernikahan anak merupakan praktik yang tersebar luas di dunia. United Nations International Children's Emergency Fund
(UNICEF) mencatat bahwa sekitar 60 \% anak perempuan didunia menikah dibawah usia 18 tahun. Indonesia termasuk negara dengan persenatase pernikahan dini tertinggi didunia (ranking 37), tertinggi kedua di Association of South East Asia Nations (ASEAN) setelah Kamboja. Perempuan muda diindonesia dengan usia 1014 tahun menikah sebanyak 0,2 \% atau lebih dari 22.000 wanita muda berusia 16-20 tahun di Indonesia sudah menikah .

Menurut Undang-Undang Perkawinan No.1 Tahun 1974 pasal 7 ayat 1 "Perkawinan hanya di izinkan jika pihak pria sudah mencapa umur 19 tahun dan pihak wanita sudah mencapai umur 16 tahun", sedangkan di lihat dari Undang-Undang Perlindungan anak No. 23 Tahun 2002 pasal 1 ayat 1 "Anak adalah seseorang yang belum berusia 18 tahun, termasuk anak yang masih dalam kandungan”. Jumlah pernikahan dini di Nusa 
Tenggara Barat (NTB) relative masih tinggi, dimana ratarata usia pernikahan dini dibawah umur 20 tahun jumlah pernikahan dini di NTB mencapai 51,5\%. Pada tahun 2014 angka pernikahan dini di NTB mencapai 50,1\% dengan usia rata-rata perkawinan di bawah 15 tahun tingkat pernikahan dini di NTB mencapai angka 58,1\%. Angka tersebut didasarkan pada hasil pendekatan keluarga tahun 2015. (BKKBN, 2015)

Ibu yang memiliki pengetahuan rendah yang memiliki anak berusia 16-20 tahun bisa menjadi penyebab terjadinya pernikahan usia dini pada remaja, hal ini sesuai dengan penelitian yang dilakukan oleh Tri Irianti (2013), menyatakan bahwa ada hubungan yang bermakna antara pengetahuan ibu tentang kesehatan reproduksi dengan tindakan responden mengawinkan puterinya di usia remaja dengan $p$ value $=0,003$. Salah satu faktor yang mempengaruhi pengetahuan diantaranya pendidikan, tingkat pendidikan ibu yang lebih tinggi lebih berhasil menunda pernikahan dini anaknya.

Umur akan mempengaruhi pengetahuan seseorang, dimana semakin tinggi umur seseorang maka kemampuannya dalam menyerap sesuatu akan baik dan pengetahuannya akan semakin bertambah, sebagian kecil ibu yang memiliki pengetahuan kurang disebabkan karena kurangnya informasi. Pekerjaan ibu akan mempunyai pengaruh terhadap kehidupan keluarga. Ibu yang bekerja biasanya meperoleh informasi lebih banyak daripada ibu yang tidak bekerja.Sosial budaya juga bisa menjadi pemicu terjadinya pernikahan dini karena pernikahan dini terjadi karena orangtua yang masih takut anaknya dikatakan perawan tua sehingga segera di kawinkan dan adanya kebiasaan yang masih melekat yaitu perjanjian antar keluarga untuk menjodohkan anaknya

\section{B. METODE PENELITIAN}

Desain penelitian yang digunakan adalah analisis deskriptif dengan pendekatan cross sectional yaitu penelitian dengan cara pendekatan, observasi atau pengumpulan data sekaligus pada waktu yang sama. Penelitian dilakukan di Kelurahan Gunung Sari. Populasi dalam penelitian ini adalah semua ibu yang memiliki anak remaja umur 16-20 tahun di Kelurahan Gunungsari berjumlah 43 orang. Sampel yang digunakan adalah semua ibu yang memiliki anak remaja usia 16-20 tahun di Kelurahan Gunung Sari sebanyak 43 orang. Teknik pengambilan sampel pada penelitian ini menggunakan sampel jenuh (total sampling). Variabel independen dalam penelitian ini adalah karakteristik ibu seperti umur ibu, pendidikan dan pekerjaan serta variabel dependen yaitu pengetahuan ibu tentang dampak pernikahan dini pada kesehatan reproduksi. Instrumen penelitian ini berupa data dari kuesioner pengetahuan ibu tentang dampak pernikahan dini pada kesehatan reproduksi. Teknik pengumpulan data menggunakan data primer dan sekunder. Analisis data meliputi analisis univariat dan bivariat dengan uji Chi Square dengan tingkat kemaknaan $\mathrm{p}<0,05$ dan tingkat kepercayaan $95 \%$.

\section{HASIL DAN PEMBAHASAN}

\section{Karakteristik ibu tentang dampak pernikahan dini pada kesehatan reproduksi bersadarkan tingkat pengetahuan}

TABEL 1

Distribusi responden berdasarkan tingkat pengetahuan

\begin{tabular}{ccc}
\hline Pengetahuan & Jumlah & Presentase (\%) \\
\hline Baik & 17 & 39.5 \\
Cukup & 18 & 41.9 \\
Kurang & 8 & 18.6 \\
\hline Total & 43 & 100.0 \\
\hline
\end{tabular}

Sumber : Data primer (2017)

Hasil penelitian menunjukkan sebagian besar berpendidikan cukup sebanyak 18 responden (41,9\%). Menurut Jaspin (2012), mengemukakan bahwa peran orang tua terhadap kelangsungan pernikahan dini pada dasarnya tidak terlepas dari tingkat pengetahuan orang tua yang dihubungkan dengan tingkat pendidikan orang tua. Oleh karena itu, tenaga kesehatan perlu memberikan penyuluhan tentang sex education

\section{Karakteristik ibu tentang dampak pernikahan dini pada kesehatan reproduksi bersadarkan umur}

Tabel 2

Distribusi responden berdasarkan umur

\begin{tabular}{ccc}
\hline Umur & Jumlah & Presentase (\%) \\
\hline$<35$ tahun & 3 & 6,9 \\
$\geq 35$ tahun & 40 & 93,02 \\
\hline Total & 43 & 100
\end{tabular}

Sumber : Data primer (2017)

Berdasarkan hasil penelitian distribusi responden berdasarkan umur sebagian besar $\geq 35$ tahun sebanyak 40 responden (93,02\%). Semakin tinggi umur seseorang maka kemampuannya dalam menyerap sesuatu akan semakin baik dan pengetahuannya akan semakin bertambah, dan sebagian kecil responden yang memiliki pengetahuan kurang karena isu-isu tersebut kurang informasi dan kurang minat untuk membaca. 
3. Karakteristik ibu tentang dampak pernikahan dini pada kesehatan reproduksi berdasarkan pendidikan.

Tabel 3

Distribusi responden berdasarkan pendidikan

\begin{tabular}{ccc}
\hline Pendidikan & Jumlah & Presentase (\%) \\
\hline Tidak Sekolah & 11 & 25,58 \\
Dasar & 26 & 60,46 \\
Menengah & 6 & 13,96 \\
Tinggi & 0 & 0 \\
\hline Total & 43 & 100 \\
\hline
\end{tabular}

Sumber : Data primer (2017)

Dari table diatas didapatkan sebagian besar berpendidikan dasar sebanyak 26 responden (60.46\%). Hal ini sesuai dengan pendapat Notoadmodjo (2012) pendidikan dapat mempengaruhi seseorang termasuk juga perilaku akan pola hidup, terutama dalam motivasi untuk sikap berperan serta dalam pembangunan kesehatan. Makin tinggi tingkat pendidikan seseorang, makin mudah menerima informasi sehingga makin banyak pula pengetahuan yang dimiliki. Sebaliknya pendidikan yang kurang akan menghambat perkembangan sikap seseorang akan nilai-nilai yang baru diperkenalkan

\section{Karakteristik ibu tentang dampak pernikahan dini pada kesehatan reproduksi bersadarkan pekerjaan}

\section{Tabel 4}

Distribusi responden berdasarkan pekerjaan

\begin{tabular}{ccc}
\hline Pekerjaan & Jumlah & Presentase (\%) \\
\hline Bekerja & 23 & 53,48 \\
Tidak bekerja & 20 & 46,51 \\
\hline Total & 43 & 100
\end{tabular}

Sumber : Data primer (2017)

Hasil penelitian menunjukkan sebagian besar responden bekerja sebanyak 23 responden (53,48\%). Menurut Nusalam (2008), bekerja umumnya merupakan kegiatan yang menyita waktu ibu yang bekerja. Bekerja bagi ibu-ibu akan mempunyai pengaruh terhadap kehidupan keluarga biasanya memperoleh informasi lebih banyak daripada ibu yang tidak bekerja.

\section{Karakteristik ibu tentang dampak pernikahan dini pada kesehatan reproduksi berdasarkan social budaya}

Tabel 5

Distribusi responden berdasarkan sosial budaya

\begin{tabular}{ccc}
\hline Sosial budaya & Jumlah & Presentase (\%) \\
\hline Mendukung & 17 & 39,53 \\
Tidak Mendukung & 26 & 60,46 \\
\hline Total & 43 & 100 \\
\hline
\end{tabular}

Sumber : Data primer (2017)

Berdasarkan hasil penelitian yang dilakukan pada responden menunjukkan hasil berdasarkan sosial budaya yaitu tidak mendukung sebanyak 26 responden (60,46\%).Menurut teori Perkawinan usia muda terjadi karena orangtua yang masih takut anaknya dikatakan perawan tua sehingga segera di kawinkan. Dan adanya kebiasaan yang masih melekat yaitu perjanjian antar keluarga untuk menjodohkan anaknya. Ada beberapa faktor yang mempengaruhi pernikahan dini yaitu faktor sosial budaya, pendidikan, ekonomi , faktor orang tua, faktor diri sendiri dan lingkungan.

6. Hubungan umur ibu dengan pengetahuan tentang dampak pernikahan dini pada kesehatan reproduksi

Tabel 6

Analisis Chi Square hubungan antara umur ibu dengan pengetahuan tentang dampak pernikahan dini pada kesehatan reproduksi.

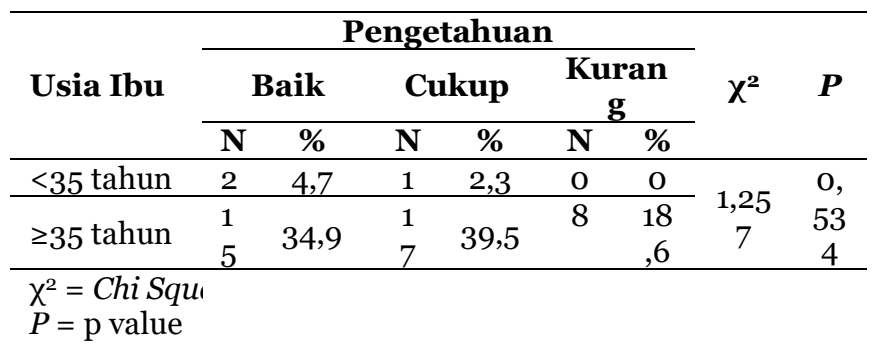

Dari hasil penelitian $p$ value 0,534 lebih besar dari 0,05 menunjukkan bahwa tidak terdapat hubungan antara umur ibu dengan pengetahuan tentang dampak pernikahan dini pada kesehatan reproduksi. Ada beberapa hal yang mempengaruhi pernikahan dini yaitu cara pandang masyarakat terutama di daerah pedesaan, terutama orang tua dari remaja. Orang tua beralasan menikahkan anakanya karena kwatir terjerumus kedalam pergaulan bebas dan berakibat negative (Mubasyaroh,2015). 


\section{Hubungan Pendidikan Ibu dengan Pengetahuan tentang dampak pernikahan dini pada kesehatan reproduksi}

Tabel 7

Analisis Chi Square hubungan antara pendidikan ibu dengan pengetahuan tentang dampak pernikahan dini pada kesehatan reproduksi.

\begin{tabular}{|c|c|c|c|c|c|c|c|}
\hline \multirow{3}{*}{$\begin{array}{l}\text { Pendidik } \\
\text { an Ibu }\end{array}$} & \multicolumn{5}{|c|}{ Pengetahuan } & \multirow{3}{*}{$x^{2}$} & \multirow{3}{*}{$P$} \\
\hline & \multicolumn{2}{|c|}{ Baik } & \multicolumn{2}{|c|}{ Cukup } & Kurang & & \\
\hline & $\mathrm{N}$ & $\%$ & $\mathrm{~N}$ & $\%$ & $\mathrm{~N} \%$ & & \\
\hline Dasar & 2 & $\begin{array}{l}4, \\
7\end{array}$ & 7 & $\begin{array}{l}16 \\
, 3\end{array}$ & 24,7 & \multirow{3}{*}{$\begin{array}{l}10 \\
, 1 \\
58\end{array}$} & \multirow{3}{*}{$\begin{array}{l}0,0 \\
38\end{array}$} \\
\hline $\begin{array}{l}\text { Menenga } \\
\mathrm{h}\end{array}$ & 13 & $\begin{array}{l}3 \\
0, \\
2\end{array}$ & 6 & 14 & $2 \quad 4,7$ & & \\
\hline Tinggi & 2 & $\begin{array}{l}4, \\
7\end{array}$ & 5 & $\begin{array}{l}11, \\
6\end{array}$ & $\begin{array}{ll}4 & 9,3\end{array}$ & & \\
\hline
\end{tabular}

$\chi^{2}=$ Chi Square

$P=$ p value

Hasil penelitian menunjukkan bahwa pendidikan memiliki pengaruh terhadap pengetahuan tentang dampak pernikahan dini pada kesehatan reproduksi. Menurut Irne (2017), menunjukkan bahwa faktor yang mempengaruhi kejadian pernikahan dini salah satunya yaitu pendidikan oarng tua. Pendidikan orang tua memiliki peranan dalam pengambilan keputusan untuk anaknya. Hal ini sejalan dengan penelitian Nandang dkk (2009), menyatakan bahwa ada hubungan pendidikan orang tua wanita dewasa muda dengan resiko sebesar 7,667 kali lipat.

8. Hubungan Pekerjaan Ibu dengan Pengetahuan tentang dampak pernikahan dini pada kesehatan reproduksi.

\section{Tabel 8}

Analisis Chi Square hubungan antara pekerjaan ibu dengan pengetahuan tentang dampak pernikahan dini pada kesehatan reproduksi.

\begin{tabular}{|c|c|c|c|c|c|c|c|c|}
\hline \multirow{3}{*}{$\begin{array}{l}\text { Pekerjaan } \\
\text { Ibu }\end{array}$} & \multicolumn{6}{|c|}{ Pengetahuan } & \multirow{3}{*}{$x^{2}$} & \multirow{3}{*}{$\boldsymbol{P}$} \\
\hline & \multicolumn{2}{|c|}{ Baik } & \multicolumn{2}{|c|}{$\begin{array}{c}\text { Cuku } \\
\text { p }\end{array}$} & \multicolumn{2}{|c|}{$\begin{array}{c}\text { Kuran } \\
\mathbf{g}\end{array}$} & & \\
\hline & $\mathbf{N}$ & $\%$ & $\mathbf{N}$ & $\%$ & $\mathbf{N}$ & $\%$ & & \\
\hline Bekerja & 9 & $\begin{array}{l}2 \\
0, \\
9\end{array}$ & 7 & $\begin{array}{l}16 \\
, 3\end{array}$ & 4 & $\begin{array}{l}9, \\
3\end{array}$ & 0,74 & 0,6 \\
\hline $\begin{array}{l}\text { Tidak } \\
\text { bekerja }\end{array}$ & 8 & $\begin{array}{l}18 \\
6\end{array}$ & $\begin{array}{l}1 \\
1\end{array}$ & $\begin{array}{l}25 \\
, 6\end{array}$ & 4 & $\begin{array}{l}9, \\
3\end{array}$ & & \\
\hline $\begin{array}{l}\chi^{2}=C h i \\
\text { Square }\end{array}$ & & & & & & & & \\
\hline
\end{tabular}

Dari hasil penelitian menunjukkan bahwa pekerjaan tidak memiliki hubungan yang signifikan dengan pengetahuan ibu tentang dampak pernikahan dini pada kesehatan reproduksi. Hal ini didukung oleh penelitian Irne (2015), menunjukkan bahwa tidak terdapat hubungan antara pekerjaan dengan kejadian pernikahan dini. P value 0,4 lebih besar dari 0,05 .
9. Hubungan Sosial Budaya dengan Pengetahuan tentang dampak pernikahan dini pada kesehatan reproduksi

\section{Tabel 9}

Analisis Chi Square hubungan antara sosial budaya dengan pengetahuan tentang dampak pernikahan dini pada kesehatan reproduksi.

\begin{tabular}{|c|c|c|c|c|c|c|c|c|}
\hline \multirow{3}{*}{$\begin{array}{l}\text { Sosial } \\
\text { Budaya }\end{array}$} & \multicolumn{6}{|c|}{ Pengetahuan } & \multirow{3}{*}{$x^{2}$} & \multirow{3}{*}{$\boldsymbol{P}$} \\
\hline & \multicolumn{2}{|c|}{ Baik } & \multicolumn{2}{|c|}{ Cukup } & \multicolumn{2}{|c|}{$\begin{array}{c}\text { Ku } \\
\text { ran } \\
\mathbf{g}\end{array}$} & & \\
\hline & $\mathbf{N}$ & $\%$ & $\mathbf{N}$ & $\%$ & $\mathbf{N}$ & $\%$ & & \\
\hline Mendukung & 3 & 7 & 10 & $\begin{array}{l}23 \\
, 3\end{array}$ & 4 & $\begin{array}{l}9 \\
6 \\
3 \\
\end{array}$ & 5, & $\mathrm{O}$, \\
\hline $\begin{array}{l}\text { Tidak } \\
\text { mendukung }\end{array}$ & 14 & $\begin{array}{l}32 \\
, 6\end{array}$ & 8 & $\begin{array}{r}18 \\
, 6\end{array}$ & 4 & $\begin{array}{l}9 \\
3 \\
3\end{array}$ & $\begin{array}{c}70 \\
6\end{array}$ & $\begin{array}{c}05 \\
8\end{array}$ \\
\hline $\begin{array}{l}\chi^{2}=\text { Chi } \\
\text { Square } \\
P=\text { p value }\end{array}$ & & & & & & & & \\
\hline
\end{tabular}

Hasil penelitian menunjukkan bahwa $p$ value lebih dari 0,05, tidak ada hubungan hubungan antara sosial budaya dengan pengetahuan tentang dampak pernikahan dini pada kesehatan reproduksi. Ada beberapa faktor yang mempengaruhi pernikahan dini yaitu faktor social budaya, pendidikan, ekonomi , faktor orang tua, faktor diri sendidri dan lingkungan. Sementara menurut Islam, pernikahan Dini adalah pernikahan yang dilakukan oleh pasangan yang belum aqil-baliq (Khaliq, 2017).

\section{KESIMPULAN DAN SARAN}

Karakteristik faktor-faktor yang mempengaruhi rendahnya pengetahuan ibu tentang pernikahan dini pada kesehatan reproduksi berdasarkan umur $\geq 35$ tahun sebanyak 3 responden $(6,9 \%)$, berdasarkan pendidikan sebanyak 22 responden $(51,16 \%)$, berdasarkan pekerjaan sebanyak 23 responden $(53,48 \%)$ dan sosial budaya sebanyak 26 responden $(60,46 \%)$. Dari beberapa karakteristik hanya pendidikan yang memiliki hubungan yang signifikan terhadap pengetahuan ibu tentang dampak pernikahan dini ( $p$ value $0,038<0,05$ ).

Diharapkan bagi peneliti selanjutnya dapat mengembangkan lagi lebih lanjut mengenai topik pernikahan dini.Seperti mempertajam aspek dampak fisik maupun psikologinya, mengembangkan variabel penelitian dan kuesioner. 


\section{DAFTAR RUJUKAN}

[1]. Irne, D. (2015). Faktor-faktor yang berhubungan terhadap Pernikahan Dini Pada Pasangan Usia Subur. JIKMU. Vol 5 No 2 April 2015 : Manado

[2]. Mubasaroh. (2016). Analisis Faktor Pernikahan Dini dan dampaknya Bagi Pelaku.YUDISIA Vol 7 No2 Desember 2016

[3]. Nursalam.SP. 2008.MetodologiRisetKeperawatan. Jakarta: CV SagungSeto

[4]. Nandang.M,Irjun.2007.Faktor-faktor yang berhubungan dengan Menikah Usia Muda pada Wanita Dewasa Muda di Kelurahan Mekarsari.Jurnal Kesehatan.Kartika STIKES Ahmad Yani.

[5]. Notoatmodjo, S. 2010. IlmuKesehatanMasyarakat. Jakarta: RinekaCipta 